\title{
强可持续理念下绿色创新效率与生态福利 绩效耦合协调的时空特征
}

\author{
肖黎明, 张仙鹏 \\ (山西师范大学经济与管理学院,临汾 041004)
}

\begin{abstract}
摘要：从强可持续理念出发,基于改进的 SFA 模型对中国 2004-2015 年 30个省份的绿色创新效 率及生态福利绩效值进行测度, 结合耦合协调度模型对两系统的耦合协调度进行分析, 同时考虑 其空间特征及演变规律。结果表明: (1)中国生态福利绩效值在空间上已形成由北京一浙江一 广东一陕西构成的四角极点支撑, 并不断向沿线地区辐射。(2)2004-2015年两系统的耦合度均值 $C \in[0.666,0.680]$, 整体处于较高强度耦合阶段, 而协调度均值则整体处于初级协调阶段 $(D \in[0.512,0.565])$, 未来仍有较大的优化空间。(3)从空间格局上看, 地区间的耦合协调度差距 显著, 高值区 (中高级协调) 主要集中在东部沿海地区, 且已形成由广东一浙江两个高级协调发 展极核辐射的“U”型发展轴带; 初级协调阶段的地区连片扩张趋势明显。相比较而言, 西北地 区仍处于中国绿色创新效率与生态福利绩效耦合协调的最后梯队, 受周边地区辐射影响较小, 增速缓慢。
\end{abstract}

关键词: 绿色创新效率;生态福利绩效;耦合协调;强可持续理念;时空特征

创新能力是国家和地区持续竞争力的重要标志，人民福祉的全面提升是经济社会发 展的根本出发点。二者的协调推进对于新时代下中国地区经济增长、人民获得感的提升 具有重要的现实意义。而在资源约束趋紧、生态环境退化的现实背景下，对二者相互关 系的探讨也应在生态边界的约束下进行 ${ }^{[1]}$, 这与十九大报告中美丽中国的建设任务相符, 同时也遵循了一种强可持续发展理念。与弱可持续相比, 强可持续更强调关键自然资本 的非减性, 认为社会发展首先应以资源和生态环境的承载能力为限, 否则, 即使实现了 增长, 也不会有长久的发展 ${ }^{[2-3]}$ 。从强可持续理念出发, 在一定的生态约束下探讨最优的

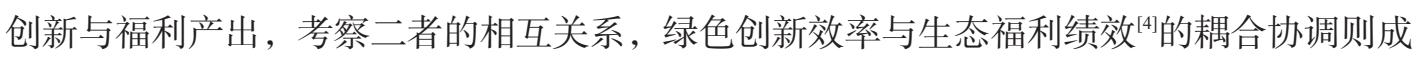
为本文的重点。

绿色创新效率，即在绿色发展要义下，尽可能利用较少的创新投人获得更多的创新 产出 ${ }^{\left[{ }^{[}\right]}$。与传统创新相比, 绿色创新效率提升首先表现为一定的环境效益 ${ }^{\left[{ }^{[}\right.}$。许多学者都 是在考虑环境效益的基础上, 对传统创新效率指标体系进行改进, 即在其中引人环境污 染、资源消耗等指标来表征 “绿色”。而对于区域绿色创新与其他系统的相关性探讨, 主 要涉及经济增长领域, 学者们分别从理论 ${ }^{[7]}$ 与实证分析 ${ }^{[8-9]}$ 层面切人, 认为绿色创新与经济 增长水平呈现 U 型关系, 即绿色创新效率的提高在短期内可能会影响经济增长速度, 但 越过增长门槛后, 就会对经济增长产生显著的助推力量。生态福利绩效是指生态投人转

收稿日期：2018-07-23；修订日期：2018-11-27

基金项目：国家社会科学基金项目（17BJY038）

作者简介：肖黎明（1972- ), 男, 山西临汾人，博士，教授，主要从事区域创新与绿色发展研究。

E-mail: xiaolm1972@163.com 
化为福利水平的效率 ${ }^{[4]}$ 。Daly ${ }^{[10]}$ 最早通过计算单位自然消耗带来的福利水平提升来评估各 国的可持续发展状况。此后，随着对生态福利绩效研究的不断深人，对其测度方法也从 单一指标 ${ }^{[1]}$ 扩展到比值法 ${ }^{[11-12]}$ 和投人产出法 ${ }^{[13-14]}$ 。对 “福利” 指标的选取一直是测度的关 键, 由于主观福利指标随机性较大, 学者多倾向选择客观福利进行表征。客观福利经历 了从 GDP 到 GNP/ISEW/CPI/HDI 的演变 ${ }^{[13]}$, 目前应用较多的指标是联合国开发计划署 UNDP 在《人类发展报告》中发布的人类发展指数（HDI），主张福利水平应该由经济、 教育和健康三个维度共同体现，具有权威性及纵向与横向的可比性 ${ }^{[1]}$ 。

目前学界对生态福利绩效的研究相对较少, 对其与绿色创新效率耦合协调的研究则更 为少见。基于此, 本文首先对生态福利绩效指标体系进行扩展，随后运用改进的 SFA 模型 对省域绿色创新效率以及生态福利绩效进行测度，结合耦合协调度模型对两大系统的耦合 协调度进行分析，同时考虑其空间特性以及演变规律，以此为各省相关政策的制定提出 建议。

\section{1 绿色创新效率——生态福利绩效耦合机制分析}

与传统创新相比, 绿色创新更加注重环境保护与资源节约的理念, 其效率的提升首 先表现为一定的环境效益。短期看, 提升绿色创新效率的初始成本较大, 可能会在一定 程度上影响区域经济增长速度; 但就长期而言, 绿色创新效率的提高作为资源约束趋紧 下的必然选择, 将成为中国经济高质量增长的强大动力源。伴随着经济的持续增长, 人 们对生态环境以及生活质量的需求进一步提升，有关环境及民生保障的政策也相继出 台。绿色创新效率的提高成为在日益严厉的环境规制下提升综合竞争力的关键, 各省均 制定相应的政策积极推动绿色创新水平的提高，生态资本投人不断加大，对生态资本的 运营也逐渐呈现有序化的发展，这对于形成良好的经济社会环境以及高层次人力资本培 养都有着积极的作用。

在以 HDI 为主要福利衡量指标的框架下, 经济与社会效益的提升都会在一定程度上 影响地区整体福利水平。这样一来, 伴随着福利产出的不断增加以及非期望投人的相对 减少, 地区生态福利绩效将会呈现不断升高的态势, 并持续从经济增长、社会包容以及 环境改善等方面对绿色创新形成更为显著的反馈：在良好的自然及社会环境下，自然资 源的可持续利用将给予人们更多的时间和空间去进行创新，以提高资源的利用效率。同 时人们生活质量的提升、获得感的增强又会促使他们积极寻求更高质量的生活水平, 包 括更健全的医疗系统、更高的就业水平以及更为全面的受教育程度等，这就为高素质人 才的培养创造了有利条件, 而这些人力资本所产生的知识性溢出又可为绿色创新研发活 动提供智力支撑, 促进绿色创新效率提升。绿色创新效率与生态福利绩效的高度耦合协 调将对中国经济增长、社会包容以及环境改善产生强大助力。因此, 准确评估中国省域 绿色创新效率与生态福利绩效的耦合协调程度并探讨其演变规律，对于推进强可持续的 美丽中国建设意义重大。

\section{2 研究方法与数据来源}

\section{1 绿色创新效率指标体系}

绿色创新旨在节能降耗、减少污染和取得持续性的经济增长, 对绿色创新效率评价 
应体现此特征 ${ }^{[15]}$ 。对于绿色创新的投人指标, 参考乔元波等 ${ }^{[5]}$ 的研究, 选取 $R \& D$ 人员全 时当量和 $R \& D$ 经费内部支出分别表征各省创新活动中的劳动和资本投人。将环境污染 ${ }^{\mathbb{1}}$ 等非期望指标作为一种未支付投入[ ${ }^{[6]}$ ，纳人绿色创新投入指标体系。而对于创新活动的产 出指标, 选取专利申请量和新产品销售收人分别反映地区自主创新能力及创新成果的经 济价值，同时使用综合能耗产出率 ${ }^{[2}$ 来测度能源利用效率 ${ }^{\left[{ }^{[1]}\right.}$ 。

\section{2 生态福利绩效指标体系}

生态福利绩效是指生态投人转化为福利水平的效率，在一定的生态投人水平或福利 水平下, 生态福利绩效反映了一个国家、地区或城市的可持续发展程度。从这个角度出 发, 生态效率的指标构建对生态福利绩效就有借鉴意义 ${ }^{[13-14,17]}$ 。而对于生态投人来说, 目 前学界很少有相关文献对其进行系统说明。学者们在研究生态效率及生态福利绩效时, 多使用环境污染、资源消耗等指标来表征生态投人。本文认为生态投人不仅应涵盖环 境、资源类指标，还应该引人一些相关资本性的投人，这样不仅可以较全面地反映地区 生态福利绩效，也可以从侧面反映生态资本投人效率，对各地区生态资本投人的相关政 策制定有一定帮助。因而借鉴相关研究 ${ }^{[18]}$, 引人生态资本投人指标, 将其从狭义上划分 为生态服务型资本、生态资源型资本以及生态环境型资本，分别选取指标来进行表征 (表1)。

有关福利产出的指标均选自联合国于 2015 年提出的《2030年可持续发展目标》 ${ }^{[19]}$ （简称SDGs）。与 HDI 相比, SDGs 将环境改善目标也作为一国可持续评价的切人点, 从 经济增长、环境改善和社会包容三个层面对国家（地区）福利水平进行评价, 是对人类 社会提出更高要求的综合发展目标 ${ }^{[20]}$ 。但 SDGs 是基于全球角度设定的目标, 对中国各 省来说, 部分指标可获性较差、可操作性不强, 所以结合中国省域经济社会发展的实际 情况，经过篮选，以代表教育、医疗和就业水平的相关指标综合表征社会包容度。在 SDGs指标体系中，环境可持续涵盖海洋、森林等多个指标，但海洋健康类指标在中国许 多省份不具适用性，所以仅保留可反映国家或地区森林资源丰富程度及实现绿化程度的 指标—— “森林覆盖率” 来表征环境福利。值得注意的是, 与传统经济衡量指标 GDP 不 同，SDGs直接以 “创新与科技” 表征一国经济发展水平，强调可持续视域下科技与创新 对一国经济增长的重要作用, 故选取 “R\&D投人占 GDP 的比例” 衡量地区经济发展水平 (表1)。

\section{3 数据来源}

由于西藏部分指标数据缺失严重, 同时为保证测算结果的准确性, 仅对 2004-2015年 除西藏及港澳台的 30 个省（市、自治区）的绿色创新效率及生态福利绩效进行测算 (Frontier 4.0 软件)。相关数据来自相应年份的《中国统计年鉴》《中国科技统计年鉴》 《中国能源统计年鉴》《中国环境统计年鉴》及《中国卫生统计年鉴》。对于受价格变动影 响的变量，均参照对应的价格指数以 2004 年的不变价格为基期进行可比价格处理 ${ }^{3} ，$ 部 分省份数据缺失采用插值法补齐。

(1) 环境污染综合值为人均工业废水、废气、固废排放量在摘值法测算下的综合值。

(2) 综合能耗产出率等于规模以上工业企业总产值与能源消耗总量之比 (元/吨标准煤)。

(3) 本文涉及的价格指数依次为地区研发价格指数 $(\mathrm{RPI}=0.75 \mathrm{PPI}+0.25 \mathrm{CPI})$ 、地区工业生产者出厂价格指数 (PPI) 、居民消费价格指数 (CPI) 、地区生产总值指数、地区固定资产投资价格指数。 
表 1 中国省际生态福利绩效评价体系

Table 1 Evaluation index system of ecological well-being performance in China

\begin{tabular}{|c|c|c|c|c|}
\hline 类别 & 一级指标 & 二级指标 & 三级指标 & 单位 \\
\hline \multirow[t]{9}{*}{ 投入指标 } & \multirow[t]{3}{*}{ 生态资本 } & \multirow{3}{*}{$\begin{array}{l}\text { 生态服务型资本 } \\
\text { 生态资源型资本 } \\
\text { 生态环境型资本 }\end{array}$} & 城市环境基础设施建设投资占地区 GDP 的比例 & $\%$ \\
\hline & & & 林业投资本年完成额占地区 GDP 的比例 & $\%$ \\
\hline & & & 环境污染治理投资总额占 GDP 的比例 ${ }^{\mathbb{D}}$ & $\%$ \\
\hline & \multirow[t]{3}{*}{ 环境污染 } & \multirow{3}{*}{$\begin{array}{l}\text { 废水排放 } \\
\text { 废气排放 } \\
\text { 固废排放 }\end{array}$} & 人均工业废水排放 & t/人 \\
\hline & & & 人均工业废气排放量 & $\mathrm{m}^{3} /$ 人 \\
\hline & & & 人均一般工业固体废物排放量 & t/人 \\
\hline & \multirow[t]{3}{*}{ 资源消耗 } & \multirow{3}{*}{$\begin{array}{l}\text { 能源消耗 } \\
\text { 土地资源消耗 } \\
\text { 水资源消耗 }\end{array}$} & 人均能源消费量 & t/人 \\
\hline & & & 人均建设用地面积 & $\mathrm{km}^{2} /$ 人 \\
\hline & & & 人均用水量 & $\mathrm{m}^{3} / 人$ \\
\hline \multirow[t]{5}{*}{ 产出指标 } & \multirow[t]{5}{*}{ 福利水平 } & 经济发展 & $R \& D$ 投入占 $G D P$ 的比例 & $\%$ \\
\hline & & 社会包容 & 失业率 & $\%$ \\
\hline & & & 各地区每千人口卫生技术人员数 & 人 \\
\hline & & & 平均受教育年限 ${ }^{2}$ & 年 \\
\hline & & 环境可持续 & 各地区森林覆盖率 & $\%$ \\
\hline
\end{tabular}

注: (1) 为避免重复,此处环境治理投资总额不包括城市环境基础设施建设投资。

(2) 平均受教育年限参照《中国人类发展报告 $2013 》$ 中的计算方法得到 ${ }^{[14]}$, 即: 平均受教育年 限 $=\frac{6 \times P_{\text {小学 }}+9 \times P_{\text {初中 }}+12 \times P_{\text {高中 }}+16 \times P_{\text {大专以上 }}, \text { 式中, } P \text { 代表各教育学历人口数。 }}{P_{\text {小学 }}+P_{\text {初中 }}+P_{\text {高中 }}+P_{\text {大专以上 }}}$

\section{4 研究方法}

采用随机前沿分析法（SFA）对绿色创新效率及生态福利绩效进行测度，但传统的 SFA 分析法只能处理单产出的效率问题, 为克服这一缺陷, 借鉴赵喜仓等 ${ }^{[2]}$ 的方法, 使 用熵值法计算绿色创新产出及福利产出的综合得分。鉴于生态福利绩效指标体系中二级 指标较多，在写人生产函数时过于繁杂，也易产生信息重叠及多重共线性问题，所以使 用同样的方法将生态福利绩效投人指标也综合为一级指标，计算出生态资本、环境污染 和资源消耗等指标的综合得分。在此基础上, 采用SFA 模型测度中国省域绿色创新效率 及生态福利绩效值，随之运用耦合协调度模型对二者的相关性进行分析。

\section{4 .1 数据标准化处理}

对数据进行标准化处理是为了消除变量间不同量纲所产生的影响，从而使数据具有 可比性。为满足标准化后的数据取对数的需求, 将目标函数调整为:

正向指标: $X_{i j t}=\frac{x_{i j t}-\min x_{j t}}{\max x_{j t}-\min x_{j t}} \times 0.9+0.1$

负向指标: $X_{i j t}=\frac{\max x_{j t}-x_{i j t}}{\max x_{j t}-\min x_{j t}} \times 0.9+0.1$

式中: $x_{i j t}$ 表示 $t$ 年 $i$ 省在第 $j$ 项指标下的原始数值; $\max x_{j t}$ 、 min $x_{j t}$ 分别表示 $t$ 年第 $j$ 指标的 最大值和最小值; $X_{i j t}$ 为变量标准化后的数值 $(t=1,2, \cdots, 12 ; i=1,2, \cdots, 30 ; j=1,2, \cdots, m)$ 。

\section{4 .2 熵值法}

熵值法作为一种客观赋权法，既可避免主观赋权的随机性，同时也能有效解决多指 标变量的信息重叠问题，具体计算步骤为： 
(1) 设选取 $m$ 个指标, $n$ 个省份。对数据进行标准化处理后，首先计算第 $t$ 年第 $j$ 项 指标下 $i$ 省份占该指标的比例:

$$
p_{i j t}=\frac{X_{i j t}}{\sum_{i=1}^{n} X_{i j t}}
$$

（2）计算第 $j$ 项指标的熵值:

$$
e_{j t}=-k \sum_{i=1}^{n} p_{i j t} \ln \left(p_{i j t}\right)
$$

式中: $k=\frac{1}{\ln (n)} ; e_{j t} \geqslant 0$ 。

（3）计算第 $j$ 项指标的差异性系数值:

$$
g_{j t}=1-e_{j t}
$$

（4）计算第 $j$ 项指标的权重:

$$
w_{j t}=\frac{g_{j t}}{\sum_{j=1}^{m} g_{j t}}, \quad(1 \leqslant j \leqslant m)
$$

（5）计算出各省份的综合得分：

$$
S_{i t}=\sum_{j=1}^{m} w_{j t} p_{i j t}
$$

\section{4 .3 效率测度模型}

与数据包络分析方法（DEA）相比, SFA方法解决了 DEA 的无统计特征, 将产出分 为生产函数、随机因素和技术无效率项三部分，因而受到众多学者的关注。但 SFA方法 需要事先设定生产函数，且应根据相关统计检验结果来确定生产函数的适用性 ${ }^{[22]}$ 。为 此，采用统计检验后的 SFA 法对绿色创新效率与生态福利绩效进行测算，以保证数据的 可比性。

以生态福利绩效值的测算为例, 由于超越对数生产函数具有一般性, 在 BatteseCoelli模型的基础上 ${ }^{[23]}$, 首先将模型设定为包含时间变量的超越对数随机前沿生产模型：

$$
\begin{aligned}
\ln Y_{i t} & =\beta_{0}+\beta_{1} t+\beta_{2} \ln B K_{i t}+\beta_{3} \ln R S_{i t}+\beta_{4} \ln E P_{i t}+\frac{1}{2} \beta_{5} t^{2}+\frac{1}{2} \beta_{6}\left(\ln B K_{i t}\right)^{2} \\
& +\frac{1}{2} \beta_{7}\left(\ln R S_{i t}\right)^{2}+\frac{1}{2} \beta_{8}\left(\ln E P_{i t}\right)^{2}+\beta_{9} t \ln B K_{i t}+\beta_{10} t \ln R S_{i t}+\beta_{11} t \ln E P_{i t} \\
& +\beta_{12} \ln B K_{i t} \ln R S_{i t}+\beta_{13} \ln B K_{i t} \ln E P_{i t}+\beta_{14} \ln R S_{i t} \ln E P_{i t}+v_{i t}-u_{i t}
\end{aligned}
$$

式中： $Y_{i t}$ 表示 $i$ 省在第 $t$ 期的福利水平 $; B K_{i t} 、 R S_{i t}$ 和 $E P_{i t}$ 分别为 $i$ 省在第 $t$ 期的生态资本投 人、资源消耗与环境污染程度; $\beta$ 为待估参数; 误差项由两个独立的部分组成, $v_{i t}$ 为独立 同分布的正态随机变量； $u_{i t}$ 反映技术无效率项。假定服从：

$$
u_{i t}=u_{i} \delta(t)=u_{i} \exp [-\eta(t-T)]
$$

式中：假设 $u_{i}$ 服从截尾正态分布 $; \eta$ 反映技术效率的变化率，则技术效率可被定义为:

$$
T E_{i t}=\exp \left(-u_{i t}\right)
$$

似然函数中所构造的方差参数为 $\gamma=\sigma_{u}^{2} / \sigma^{2}, \sigma^{2}=\sigma_{u}^{2}+\sigma^{2}{ }_{v}$, 通过 $\gamma$ 取值, 可判断该类数据 是否可以使用 SFA方法测算。

绿色创新效率的测算模型也采取同样的构建方法，限于篇幅，不再赘述。为确定所 选的超越对数随机前沿模型是否适用，本文采用似然比（LR）进行检验。广义似然比的 
统计量 $L R$ 为:

$$
L R=-2 \times\left[\ln L\left(H_{0}\right)-\ln L\left(H_{1}\right)\right]
$$

检验统计量服从混合卡方分布，即 $L R \sim \chi_{1-\alpha}^{2}(k)$, 式中: $\alpha$ 为显著性水平; 自由度 $K$ 为受约束变量数。

\section{4 .4 耦合协调度模型}

耦合度是一个物理学概念, 反映多个不同的系统参量相互影响、相互作用的紧密程 度。但当不同系统均处于较低水平时, 也可能会出现较高耦合度 ${ }^{[2]}$ 。而协调度则是对系 统耦合度认识的深化，主要度量系统间或系统组成要素在发展过程中的平衡状态及其和 谐程度 ${ }^{[25]}$ 。鉴于此，本文构建耦合协调度模型，考察中国省域绿色创新效率与生态福利 绩效交互作用的有序性及整体协调程度，具体模型为：

$$
\begin{gathered}
C=2\left\{\left(G_{1} \cdot E_{1}\right) /\left[\left(G_{1}+E_{1}\right)\left(E_{1}+G_{1}\right)\right]\right\}^{1 / 2} \\
H=\alpha G_{1}+\beta E_{1} \\
D=(C \cdot H)^{1 / 2}
\end{gathered}
$$

式中: $G_{1}$ 与 $E_{1}$ 分别表示绿色创新效率和生态福利绩效值; $C$ 为耦合度; $H$ 表示二者的综 合调和指数; $D$ 为系统耦合协调度; $\alpha 、 \beta$ 为待定系数, 主要衡量各系统的重要程度（贡献

\begin{tabular}{|c|c|c|c|c|}
\hline & 区间 & 耦合等级 & \multicolumn{2}{|c|}{ 特征 } \\
\hline \multirow[t]{4}{*}{ 耦合度 $C$} & $0 \leqslant C<0.3$ & 低度耦合 & \multicolumn{2}{|l|}{ 相互关联性不强 } \\
\hline & $0.3 \leqslant C<0.5$ & 拮抗(中强度)耦合 & \multicolumn{2}{|c|}{ 相互关联性增强，同时产生抑制 } \\
\hline & $0.5 \leqslant C<0.8$ & 较高强度耦合 & \multicolumn{2}{|l|}{ 系统进人良性耦合 } \\
\hline & $0.8 \leqslant C<1.0$ & 高强度耦合 & \multicolumn{2}{|l|}{ 良好共振，共同促进发展 } \\
\hline \multirow[t]{5}{*}{ 协调度 $D$} & $0 \leqslant D<0.2$ & 严重失调 & \multirow{5}{*}{$\begin{array}{l}G_{1}-E_{1}>0.1 \\
E_{1}-G_{1}>0.1 \\
0 \leqslant\left|G_{1}-E_{1}\right| \leqslant 0.1\end{array}$} & \multirow{5}{*}{$\begin{array}{l}\text { 生态福利绩效滞后 } \\
\text { 绿色创新效率滞后 } \\
\text { 相对协调发展 }\end{array}$} \\
\hline & $0.2 \leqslant D<0.4$ & 濒临失调 & & \\
\hline & $0.4 \leqslant D<0.6$ & 初级协调 & & \\
\hline & $0.6 \leqslant D<0.8$ & 中级协调 & & \\
\hline & $0.8 \leqslant D<1.0$ & 高级协调 & & \\
\hline
\end{tabular}
份额）, 取 $\alpha=\beta=0.5^{[24]}$ 。根据耦合协调度 $D$ 以及 $G_{1}$ 与 $E_{1}$ 的测算值，可作如下划分 ${ }^{[25]}$ (表 2)。

\section{表 2 耦合协调度等级划分}

Table 2 Ranking of coupling and coordinating degree

\section{3 结果分析}

\section{1 绿色创新效率与生态福利绩效测算}

基于改进后的 SFA 模型对 2004-2015 年中国 30个省市绿色创新效率及其生态福利绩 效进行测度，为保证结果的稳健性，首先对模型的适用性进行检验（表 3)。模型（1） （绿色创新效率）与模型（2）（生态福利绩效）的检验结果均拒绝原假设，且其 $\gamma$ 值分别 为 0.91137 和 0.96141 , 二者均在 $5 \%$ 的显著水平上通过了 $t$ 检验, 说明复合误差项的变异 主要是由无效率项引起的。进一步的统计检验结果（检验 1）也表明，选用 SFA 模型可 以较好地刻画地区绿色创新效率及生态福利绩效。检验2 检验 5 的结果则表明，在模型 
表 3 前沿生产函数模型统计检验结果

Table 3 Statistical test results of Stochastic Frontier Function model

\begin{tabular}{|c|c|c|c|c|c|}
\hline \multirow[t]{2}{*}{ 原假设 } & \multicolumn{2}{|c|}{$L R$} & \multirow[t]{2}{*}{ 自由度 $K$} & \multicolumn{2}{|c|}{ 结论 } \\
\hline & 模型（1） & 模型（2） & & 模型（1） & 模型（2） \\
\hline 检验 $1: H_{0}: \gamma=0$ & 324.62 & 719.82 & 3 & 拒绝 ${ }^{* * *}$ & 拒绝*** \\
\hline 检验 2: $H_{0}: \beta_{5}=\beta_{6}=\beta_{7}=\beta_{8}=\beta_{9}=\beta_{10}=\beta_{11}=\beta_{12}=\beta_{13}=\beta_{14}=0$ & 62.85 & 16.81 & 3 & 拒绝 ${ }^{* * *}$ & 拒绝*** \\
\hline 检验 3: $H_{0}: \beta_{1}=\beta_{5}=\beta_{9}=\beta_{10}=\beta_{11}=0$ & 19.79 & 74.50 & 3 & 拒绝 ${ }^{* * *}$ & 拒绝 ${ }^{* * *}$ \\
\hline 检验 $4: H_{0}: \beta_{9}=\beta_{10}=\beta_{11}=0$ & 10.26 & 10.18 & 3 & 拒绝 ${ }^{* *}$ & 拒绝** \\
\hline 检验 $5: H_{0}: \eta=0$ & 3.80 & 8.63 & 2 & 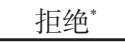 & 拒绝 ${ }^{* * *}$ \\
\hline
\end{tabular}

注: ${ }^{* * *}$ 、** “分别表示在 $1 \% 、 5 \%$ 和 $10 \%$ 的显著水平上拒绝原假设。

的具体设定上，应选用包含时间变量的超越对数随机前沿生产函数，这与最初设定模型 相符。且模型 $(2)$ 的回归结果中 $\beta_{2} 、 \beta_{6} 、 \beta_{9} 、 \beta_{12} 、 \beta_{13}$ 的估计系数分别为 0.412 $\left(2.58^{* *}\right) 、 0.049\left(1.871^{*}\right) 、-0.012\left(-2.947^{* * *}\right) 、 0.051(1.586) 、-0.017(-1.198) ，$ 除 $\beta_{12} 、$ $\beta_{13}$ 外，均通过了 $t$ 检验，表明在生态福利绩效指标体系中引人生态资本投人指标具有一定 的合理性。进一步利用ArcGIS 10.5 软件对研究期内 2004年和 2015 年的绿色创新效率和 生态福利绩效测算结果进行空间可视化处理（图 1)。
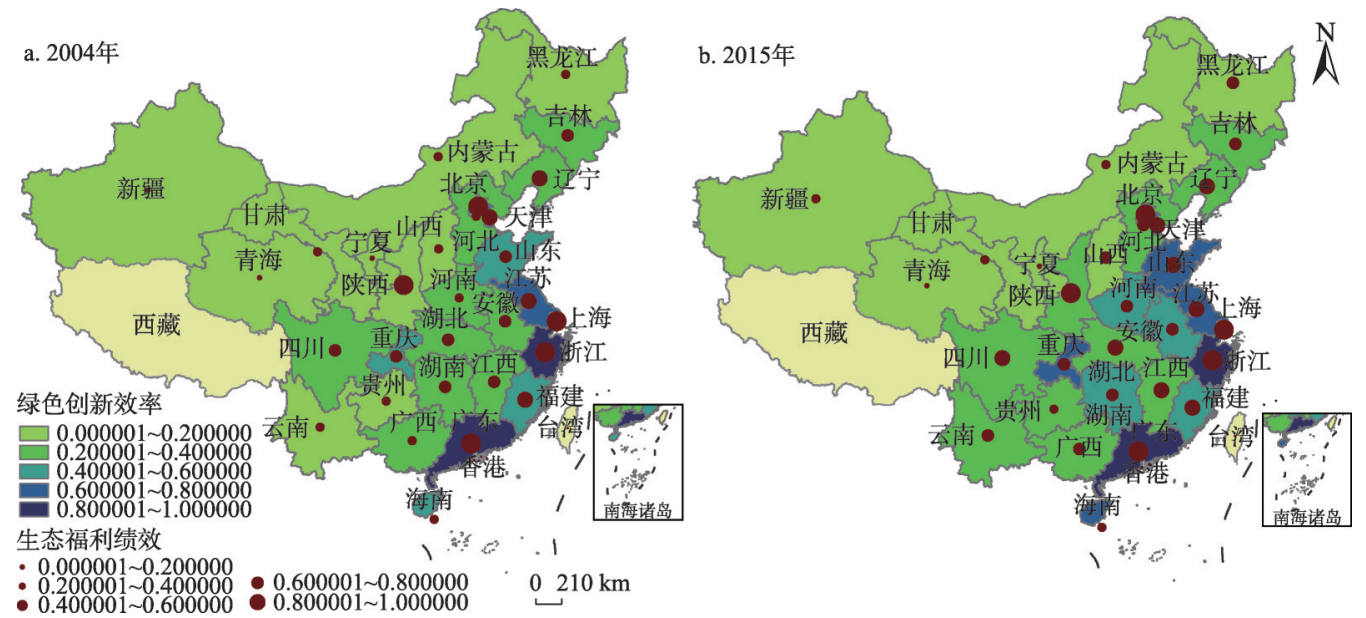

注：本图基于国家测绘地理信息局标准地图服务网站下载审图号为 GS(2016)1547 的标准地图制作，底图无修改，下同。

图 1 中国绿色创新效率与生态福利绩效的空间演变格局

Fig. 1 The spatial evolution pattern of green innovation efficiency and ecological well-being performance in China

\section{1 .1 绿色创新效率的演变特征和空间格局}

总体上，中国地区绿色创新水平呈逐年上升态势，但发展水平却较低，2015年全国 平均值仅为 0.419 , 仍有约 $58 \%$ 的提升空间。省域层面看，绿色创新效率排名前十的省份 有广东、浙江、上海、江苏、天津、重庆、山东、海南、福建和北京。除重庆外，基本 都位于东部沿海地区，与已有研究结论基本一致 ${ }^{[5]}$ 。这是因为东部地区技术市场发展较完 善、科技投人大，加之可持续发展理念不断深人，更加注重资源的有序利用和环境保 护，绿色创新效率随之提高。值得注意的是，位于东部的河北省绿色创新效率值较低， 与其经济发展水平不吻合，排名位于后十一，2004-2015 年的绿色创新效率均值仅为 0.243 ，与北京（0.432）和天津（0.678）呈现三阶梯度递减格局。造成这种现象的原因 
可能是由于河北经济发展的驱动因素长期依靠能源综合供给能力, 高污染企业居多, 创 新能力不足，粗放的发展方式使其绿色转型成本巨大。此外，北京虽然科技投人巨大， 但其绿色创新效率不如天津，某些年份的新产品销售收人及专利申请量都低于天津，未 来应加强资金监管和运营，实现京津冀绿色创新的协同发展。排名后十位的省份除山西 外, 均属于西部地区。山西作为中国的能源资源大省, 同样面临经济绿色转型的阵痛, 转型成本和压力巨大，这直接导致其绿色创新效率低下。从东、中、西部以及东北的空 间格局看（图 1)，地区间呈现较大差异性。2004年中国绿色创新效率高值省份基本都位 于东部沿海地区，整体上呈现出由东向西的层级递减格局。到了 2015 年，各省绿色创新 效率都有不同程度提高，绿色创新效率高值分布区域呈现出以广东一浙江为辐射核心的 “U”型发展轴带，且不断向中西部地区深人。

\section{1 .2 生态福利绩效演变特征和空间格局}

中国各地生态福利绩效均值排名与绿色创新效率均值排名基本一致，大致呈现由东 向西、由东向东北的梯度递减格局，但某些省份的具体排名与绿色创新效率排名相比变 动较大。排名前十的省份包括北京、陕西、上海、浙江、广东、天津、福建、辽宁、江 苏、四川，东部省份居多，但一些西部省份（陕西、四川）和东北省份（辽宁）排名靠 前。北京的生态福利绩效（1.000）稳居全国第一，这是因为北京作为全国经济政治文化 中心，生态资本和科技投人都位居前列，三产的蓬勃发展也为北京带来了良好的就业前 景，加之相关政策倾斜和生态文明理念推进，北京更加注重对其生态环境、教育和医疗 卫生的投人，生态福利绩效大幅领先周围省市，形成较稳定的辐射核心。陕西（0.934） 地处内陆腹地，区位优势虽不及东部省市，但凭借其独特的文化资源及交通优势，依托 西部大开发战略，已发展为一个集高质量经济、教育、医疗、环境为一体的综合型大 省。未来陕西发展潜力巨大，在抢占西部发展龙头的同时，有望成为连接各生态空间的 绿色廊道。辽宁（0.710）作为国家老工业基地，基础设施完善，综合实力较强，近年对 资源环境的管理也在逐渐规范，使其生态福利绩效处于全国较高水平。整体上看，虽然 各地生态福利绩效均值排名仍旧呈现由东向西递减的格局，但随着西部省份不断挤身全 国前列，中国生态福利绩效的空间格局将大体呈现由东向西的 “高一低一高一低” 的空 间格局，形成了由北京一浙江一广东一陕西构成的四角极点支撑，并不断向周边地区辐 射。排名后五位的省份（青海、宁夏、新疆、甘肃、海南）大都位于西部地区。海南虽 位于东部沿海地区，但其整体生态福利较低，2004-2015 年的均值仅为 0.287 。这是因为 海南远离大陆，没有深水港口，无法停靠大型运输船只，长期以来依靠旅游业创收，虽 然生态环境保护较好，但经济结构单一、整体发展不足导致其生态福利绩效远落后于近 邻广东。

\section{2 耦合协调分析}

由图 2 可知，2004-2015 年中国省域绿色创新效率与生态福利绩效的耦合度及协调度 均值都呈逐年升高态势, 其中耦合度均值 $C \in[0.666,0.680]$, 整体处于较高强度耦合阶 段，表明绿色创新效率与生态福利绩效关联性较强，系统进人良性耦合。而协调度均值 $D \in[0.512,0.565]$, 整体处于初级协调阶段，未来仍有较大的优化空间。由于耦合度只能 判别系统间互相作用的强弱程度和方向特征，当不同系统均处于较低水平时，也可能会出 现较高耦合度，因此本文着重对二者的协调度进行分析。为考察中国省域耦合协调度的 时空演变规律，根据表 2 对各省耦合协调度的测算结果进行分类（表4)，同时根据两系统 
差额的绝对值绘制柱状图（图 3)。且 从本文对生态福利绩效的分析中也可 以发现，随着一些西部省份排名跻身 全国前列和一些东部省份排名下滑, 传统的东、中、西、东北四大板块的 区域划分已不能满足现有分析需求, 所以为了提高区域分析的精准度, 本 文将西部地区进一步细分为西北和西 南地区 ${ }^{4}$ 。

\subsection{1 绿色创新效率与生态福利绩效} 耦合协调度的演变特征



图 2 中国绿色创新效率与生态福利绩效 耦合度与协调度变动趋势

Fig. 2 The coupling degree and coordination degree of green innovation and ecological well-being in China

从表 4 可以看出，2004年中国各省绿色创新效率与生态福利绩效的堣合协调度主要 处于初级协调水平，高级协调以及严重失调的省份数量为零，表明二者具有一定的正相 关性，但整体水平有待进一步提升。处于濒临失调阶段的省份包括黑龙江、内蒙古、山 西、宁夏、甘肃、青海、新疆、贵州, 占总研究样本的 $27 \%$, 除山西、内蒙古、黑龙江 属于 “濒临失调一绿色创新滞后” 发展类型外，其余省份均实现了绿色创新效率与生态 福利绩效的相对协调发展。山西、内蒙古和黑龙江属于资源型省份，煤炭资源丰富，长 期以来依靠粗放的发展方式，导致绿色转型成本过大，绿色创新动力不足。处于初级协 调的省份相对较多，占总研究样本的 $47 \%$ 。其中只有安徽、河南、湖南基本实现了初级 协调阶段的相对协调发展。位于中级协调阶段的省份全部处于东部地区，除北京、上 海、福建等属于绿色创新滞后类型外，其余省份均实现了相对协调发展。

\section{表 4 中国各省绿色创新效率与生态福利绩效耦合协调度分类}

Table 4 The classification of the coupling and coordinating degree in Chinese provinces

\begin{tabular}{|c|c|c|c|c|c|}
\hline & 严重失调 & 濒临失调 & 初级协调 & 中级协调 & 高级协调 \\
\hline 2004年 & --- & $\begin{array}{l}\text { 山西*, 内蒙古*, } \\
\text { 黑龙江*, 贵州, 甘 } \\
\text { 肃, 青海, 宁夏, } \\
\text { 新疆 }\end{array}$ & 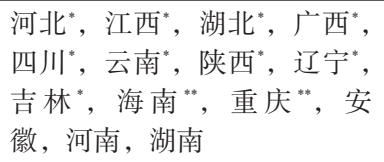 & $\begin{array}{l}\text { 北京 }{ }^{*}, \text { 上海 }{ }^{*} \text {, 福建 }{ }^{*} \text {, } \\
\text { 天津, 江苏, 浙江, 山 } \\
\text { 东, 广东 }\end{array}$ & --- \\
\hline 2015 年 & --- & 宁夏", 青海, 新疆 & 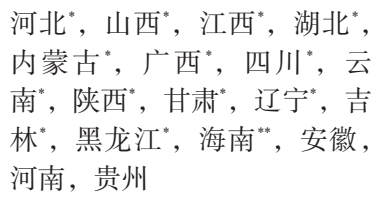 & 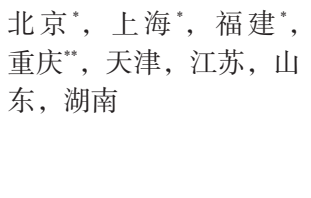 & 广东, 浙江 \\
\hline
\end{tabular}

注: : “分别表示绿色创新效率相对滞后类型和生态福利绩效相对滞后类型。

至 2015 年，濒临失调的省份仅剩下宁夏、新疆和青海三省，而初级协调阶段的省份 则进一步扩大，由 14 个变为 17 个，占总研究样本的 $57 \%$ 。从表 4 还可以看出，初级协调 阶段的省份大多未实现相对协调发展，属于生态福利绩效滞后类型的省份只有 1 个，而 绿色创新效率滞后类型的则有 13 个, 表明在初级协调阶段, 各省不均衡发展问题突出, 单极驱动的发展方式阻碍了各省实现进一步跃迁的进度，也直接造成了初级协调阶段省

(4) 参考已有文献 ${ }^{[201}$ 将西部地区划分为西北地区和西南地区，其中西南地区包括广西、重庆、四川、贵州和云 南; 西北地区包括内蒙古，陕西、甘肃、青海、宁夏和新疆。 
份数量的堆积。重庆、湖南两地从初级协调阶段跃迁至中级协调阶段, 绿色创新效率及 生态福利绩效有都相对提高，但重庆仍属于生态福利滞后型。处于中级协调阶段的部分 省份虽仍存在绿色创新效率与生态福利绩效发展不协调的问题，但二者的差距随时间推 移而不断缩小（图 3)。而凭借较强的综合实力以及绿色创新能力，广东、浙江两省率先 从中级协调跃迁至高级协调，实现了绿色创新效率与生态福利绩效的协调推进，可持续 发展能力强劲。

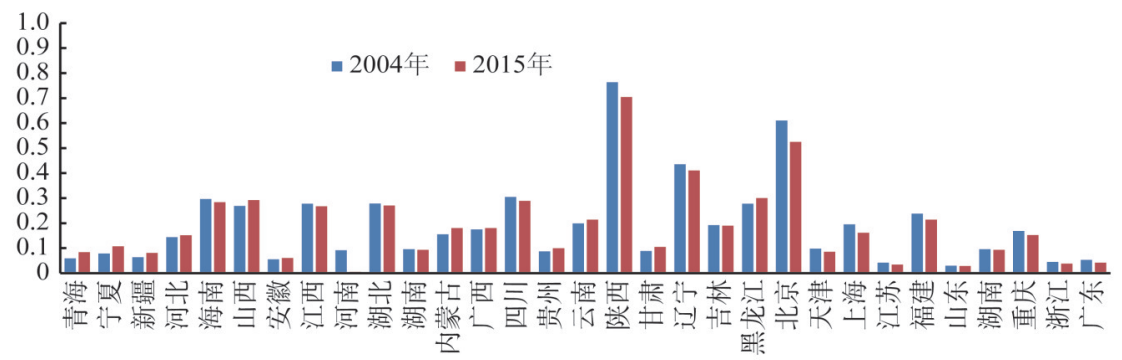

图 32004 年和 2015 年中国绿色创新效率与生态福利绩效差额绝对值对比

Fig. 3 Comparison of the absolute value difference between green innovation efficiency and ecological well-being performance in China in 2004 and 2015

\subsection{2 绿色创新效率与生态福利绩效耦合协调度的空间演变格局}

根据表 2 的分类法，运用ArcGIS 10.5 软件对中国绿色创新效率与生态福利绩效耦合 协调度的测度值进行空间可视化处理，得到 2004 年和 2015 年耦合协调度的空间演化格局 图（图 4)。从图 4可以看出，中国省域绿色创新效率与生态福利绩效的耦合协调度具有 明显的空间分异规律，各地区的空间异质性显著。2004年，协调度较高的省市基本都位 于东部地区，且整体呈现由东向西的梯度递减格局，西北（0.324）和西南（0.474）差距 显著, 进一步说明对区划进行细分的必要性。至 2015 年, 全国整体的耦合协调度有了较 大提升，各省差距虽有缩小（耦合协调度最高省份与最低省份的差值从 0.582 缩至 $0.552)$ ，但从空间格局看，地区间的差距依然很大。高值区仍主要集中于东部，且已形
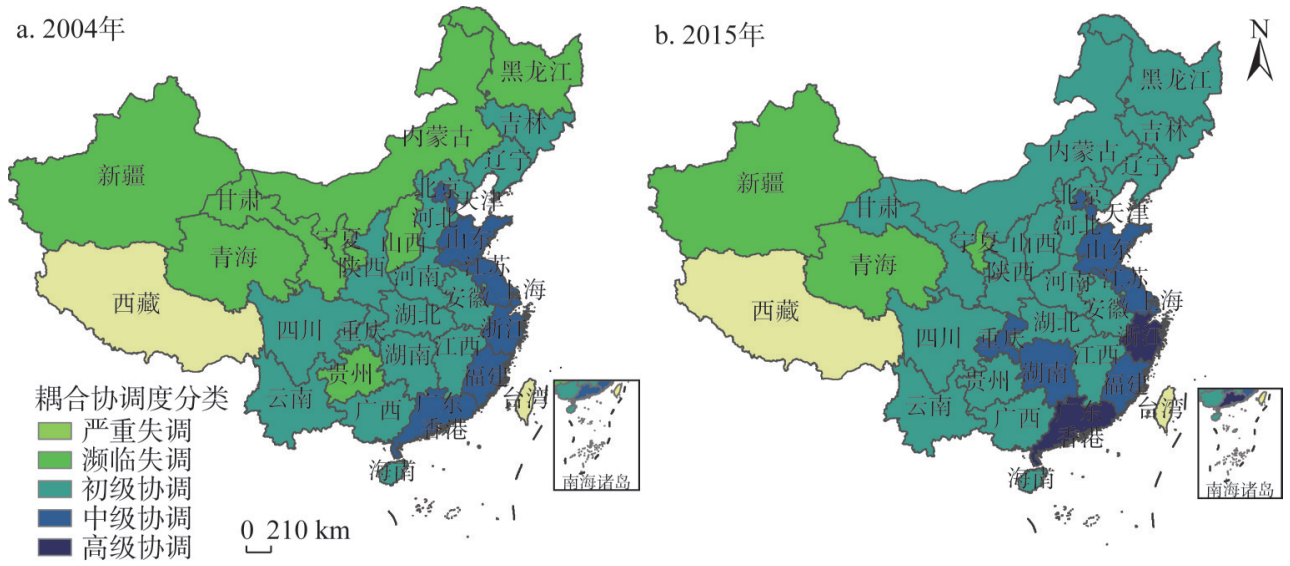

图 4 中国绿色创新效率与生态福利绩效耦合协调度空间演变格局

Fig. 4 The spatial evolution pattern of coupling and coordination degree in China 
成由广东 (0.806) 一浙江（0.800）两个高级协调发展极核辐射的“U”型发展轴带。处 于中级协调阶段的省份自广东向北增加了湖南（中部）、重庆（西南）两省，未来有望继 续发挥广东和深圳的辐射核心作用，实现耦合协调高值区由广东一内陆，浙江一东部沿 海的深人。初级协调阶段的地区连片扩张趋势明显，东部、中部、西北、西南和东北部 地区的省份均有涉及。相比较而言，西北地区（0.393）受经济条件和区位因素限制，绿 色创新效率和生态福利绩效均较低，未能形成良性互动，仍处于耦合协调的最后梯队。

\section{4 结论与讨论}

本文基于改进的 SFA 模型对中国 2004-2015 年30个省份的绿色创新效率及生态福利 绩效进行测度，结合耦合协调度模型对两系统的耦合协调度进行分析，划分不同类型， 同时考虑其空间特性以及演变规律，研究结论及启示如下：

（1）中国省域绿色创新效率虽然呈现出逐年升高的态势，但发展水平仍较低，地区 间表现出较大差异性。生态福利绩效在空间上形成了由北京一浙江一广东一陕西构成的 四角极点支撑，并不断向沿线地区辐射。未来在依靠东部发达地区对周边地区帮扶的同 时, 西部地区可以陕西为枢纽, 把握 “一带一路” 建设所带来的契机, 提升沿线地区绿 色创新效率和生态福利绩效水平及成果转化，实现可持续发展。

（2）研究期内中国各省的耦合协调度均有不同程度上升，但整体仍处于初级协调阶 段。低等级耦合协调度的跃迁主要依靠绿色创新效率或生态福利绩效的单极带动, 但跃 迁至初级协调阶段后，由于不协调发展问题凸显，进一步跃迁难度加大，因而处于初级 协调阶段的省份急需整合资源，实现二者良性互助，推动其向中高级协调跃迁。

（3）从空间格局演化上看，各省份以及地区间的耦合协调度差距显著。高值区主要 集中在东部地区，并且已经形成由广东一浙江两个高级协调发展极核辐射的 “U” 型发 展轴带。初级协调阶段地区的连片扩张趋势明显。相比较而言, 西北地区仍处于中国绿 色创新与生态福利耦合协调的最后梯队，受到周边地区辐射影响较小，增速缓慢。未来 应继续以广东、浙江为切人点, 发挥其辐射带动作用, 形成高级协调区发展轴带的横向 扩展（东一西南）与纵向深化（东一中一西北）。

\section{参考文献(References):}

[1] 冯吉芳, 袁健红. 生态福利绩效: 可持续发展新的分析工具. 科技管理研究, 2016, (12): 240-244. [FENG J F, YUAN J H. Ecological welfare performance: A new analysis tool for sustainable development. Science and Technology Management Research, 2016, (12): 240-244.]

[2] MORAN D D, MATHIS W, KITZES J A, et al. Measuring sustainable development: Nation by nation. Ecological Economics, 2008, 64(3): 470-474.

[3] NEUMAYER E. Weak Versus Strong Sustainability: Exploring the Limits of Two Opposing Paradigms. Cheltenham: Edward Elgar, 2010.

[4] 诸大建, 张帅. 生态福利绩效与深化可持续发展的研究. 同济大学学报: 社会科学版, 2014, 25(5): 106-115. [ZHU D J, ZHANG S. Ecological wellbeing performance and further research on sustainable development. Tongji University Journal Social Science Section, 2014, 25(5): 106-115.]

[5] 乔元波, 王砚羽. 基于三阶段 DEA-Windows 分析的中国省域创新效率评价. 科学学与科学技术管理, 2017, 38(1): 88-97. [QIAO Y B, WANG Y Y. The evaluation of innovation efficiency in China based on three-stage DEA-Windows. Science of Science and Management of Science \& Technology, 2017, 38(1): 88-97.]

[6] 曹霞, 于娟. 绿色低碳视角下中国区域创新效率研究. 中国人口·资源与环境, 2015, 25(5): 10-19. [CAO X, YU J. Re- 
gional innovation efficiency in China from the green low-carbon perspective. China Population, Resources and Environment, 2015, 25(5): 10-19.]

[7] 何小钢. 能源约束、绿色技术创新与可持续增长: 理论模型与经验证据. 中南财经政法大学学报, 2015, (4): 30-38. [HE X G. The constraint of energy, green technology innovation and sustainable growth: Theoretical model and empirical evidence. Journal of Zhongnan University of Economics and Law, 2015, (4): 30-38.]

[8] 陈艳春, 韩伯棠, 岐洁. 中国绿色技术的创新绩效与扩散动力. 北京理工大学学报: 社会科学版, 2014, 16(4): 50-56. [CHEN Y C, HAN B T, QI J. The innovation performance and diffusion driven force of green technology in China. Journal of Beijing Institute of Technology: Social Sciences Edition, 2014, 16(4): 50-56.]

[9] 张振刚, 白争辉, 陈志明. 绿色创新与经济增长的多变量协整关系研究: 基于 1989-2011年广东省数据. 科技进步与 对策, 2014, 31(10): 24-30. [ZHANG Z G, BAI Z H, CHEN Z M. Multivariate cointegration relationship between green innovation and economic growth: Based on the yearly data of Guangdong between 1989 and 2011. Science \& Technology Progress and Policy, 2014, 31(10): 24-30.]

[10] Daly H E. A further critique of growth economics. Ecological Economics, 2013, 88: 20-24.

[11] 诸大建, 张帅. 生态福利绩效及其与经济增长的关系研究. 中国人口·资源与环境, 2014, 24(9): 59-67. [ZHU D J, ZHANG S. Research on ecological wellbeing performance and its relationship with economic growth. China Population, Resources and Environment, 2014, 24(9): 59-67.]

[12] 㶓漫丹, 诸大建, 刘国平. 生态福利绩效: 概念、内涵及 G20 实证. 中国人口・资源与环境, 2013, 23(5): 118-124. [ZANG M D, ZHU D J, LIU G P. Ecological well-being performance: Concept, connotation and empirical of G20. China Population, Resources and Environment, 2013, 23(5): 118-124.]

[13] 龙亮军, 王霞. 上海市生态福利绩效评价研究. 中国人口·资源与环境, 2017, 27(2): 84-92. [LONG L J, WANG X. A study on Shanghai's ecological well-being performance. China Population, Resources and Environment, 2017, 27(2): 84-92.]

[14] 龙亮军, 王霞, 郭兵. 基于改进 DEA 模型的城市生态福利绩效评价研究: 以我国 35 个大中城市为例. 自然资源学 报, 2017, 32(4): 595-605. [LONG L J, WANG X, GUO B. Evaluation of urban ecological well-being performance based on revised DEA model: A case study of 35 major cities in China. Journal of Natural Resources, 2017, 32(4): 595-605.]

[15] 张逸昕, 林秀梅. 中国省际绿色创新效率与系统协调度双演化研究. 当代经济研究, 2015, (3): 51-56. [ZHANG Y X, LIN X M. The double evolution of system coordination degree of provincial green innovation efficiency in China. Contemporary Economic Research, 2015, (3): 51-56.]

[16] 肖黎明, 高军峰, 刘帅. 基于空间梯度的我国地区绿色技术创新效率的变化趋势: 省际面板数据的经验分析. 软科 学, 2017, 31(9): 63-68. [XIAO L M, GAO J F, LIU S. The change trend of green technology innovation efficiency in China based on spatial gradient: Empirical analysis of provincial panel data. Soft Science, 2017, 31(9): 63-68.]

[17] 张晓娣. 生态效率变动的产业及要素推动: 基于投人产出和系统优化模型. 自然资源学报, 2015, 30(5): 748-760. [ZHANG X D. Eco-efficiency change driven by products and factors: Combining input-output and system optimization models. Journal of Natural Resources, 2015, 30(5): 748-760.]

[18] 严立冬, 屈志光, 黄鹏. 经济绿色转型视域下的生态资本效率研究. 中国人口 - 资源与环境, 2013, 23(4): 18-23. [YAN L D, QU Z G, HUANG L. Research on ecological capital efficiency under the perspective of green economic transition. China Population, Resources and Environment, 2013, 23(4): 18-23.]

[19] SACH J, SCHMIDT-TRAUB G, KROLL C. SDG index and dashboard-global report. New York: Bertelsmann Stiftung and Sustainable Development Solutions Network, 2016: 11-52.

[20] 薛澜,翁凌飞. 中国实现联合国 2030 年可持续发展目标的政策机遇和挑战. 中国软科学, 2017, (1): 1-12. [XUE L, WENG L F. The policy opportunities and challenges in China's implementation of 2030 sustainable development goals. China Soft Science, 2017,(1): 1-12.]

[21] 赵喜仓, 安荣花. 江苏省科技成果转化效率及其影响因素分析: 基于熵值和随机前沿的实证分析. 科技管理研究, 2013, (9): 81-85. [ZHAO X C, AN R H. Transformation efficiency of sci-tech achievements and influence factors in Jiangsu province: Empirical analysis based on entropy and stochastic frontier function. Science and Technology Management Research, 2013, (9): 81-85.]

[22] 张乐, 曹静. 中国农业全要素生产率增长: 配置效率变化的引人: 基于随机前沿生产函数法的实证分析. 中国农村 经济, 2013, (3): 4-15. [ZHANG L, CAO J. TFP growth in China: The introduction of changes in allocation efficiency: An empirical analysis based on stochastic frontier production function. Chinese Rural Economy, 2013, (3): 4-15.]

[23] BATTESE G E, COELLI T J. Frontier production functions, technical efficiency and panel data: With application to paddy farmers in India. Journal of Productivity Analysis, 1992, 3(6): 153-169.

[24] 王少剑, 方创琳, 王洋. 京津冀地区城市化与生态环境交互耦合关系定量测度. 生态学报, 2015, 35(7): $2244-2254$. [WANG S J, FANG C L, WANG Y. Quantitative investigation of the interactive coupling relationship between urbanization and eco-environment. Acta Ecologica Sinica, 2015, 35(7): 2244-2254.] 
[25] 张荣天, 焦华富. 泛长江三角洲地区经济发展与生态环境耦合协调关系分析. 长江流域资源与环境, 2015, 24(5): 719-727. [ZHANG R T, JIAO H F. Coupling and coordinating between economic development and ecological environment in the Pan Yangtze River Delta. Resources and Environment in the Yangtze Basin, 2015, 24(5): 719-727.]

[26] 邹璇, 贾蕾玉. 工业能源消耗结构的优化路径及地区差异. 软科学, 2017, 31(6): 46-50. [ZOU X, JIA L Y. The optimal path and regional differences of the industrial energy consumption structure. Soft Science, 2017, 31(6): 46-50.]

\title{
Spatio-temporal characteristics of coupling coordination between green innovation efficiency and ecological welfare performance under the concept of strong sustainability
}

\author{
XIAO Li-ming, ZHANG Xian-peng \\ (School of Economics and Management, Shanxi Normal University, Linfen 041004, Shanxi, China)
}

\begin{abstract}
Starting from the concept of strong sustainability, we measure the green innovation efficiency and ecological welfare performance of 30 provinces in China from 2004 to 2015 based on the improved SFA model. We analyze the degree of the coupling coordination of the two systems with a coupling-coordination model, taking into account their spatial characteristics and evolution rules. The results show that: (1) China's ecological welfare performance value has been spatially supported by a quadrangular pole composed of Beijing, Zhejiang, Guangdong and Shaanxi, and continues to radiate to the areas along the lines. (2) The average coupling degree of the two systems in 2004-2015 is $C \in[0.666,0.680]$, which is in the stage of high intensity coupling, while the average coordination degree is in the stage of elementary coordination $(D \in[0.512,0.565])$, meaning that there is still large improvement space in the future. (3) In terms of spatial pattern, there is a significant gap in the degree of coupling coordination between different regions. The high-value areas (midium- and high-level coordination) are mainly concentrated in the eastern coastal areas, and have formed a "U"-shaped development axis of polar nuclear radiation coordination between Guangdong and Zhejiang. At the elementary coordination stage, the trend of connected regional expansion is obvious. In comparison, the northwest region is still in the final echelon of the coupling coordination between China's green innovation efficiency and ecological welfare performance. It is less affected by the radiation from the surrounding areas and the growth rate is slow.
\end{abstract}

Keywords: green innovation efficiency; ecological welfare performance; coupling and coordination; strong sustainable perspective; spatio-temporal characteristics 